\title{
Prevalence and risk factors of moderate to severe obstructive sleep apnea syndrome in major depression: a observational and retrospective study on 703 subjects
}

\author{
Matthieu Hein*, Jean-Pol Lanquart, Gwenolé Loas, Philippe Hubain and Paul Linkowski
}

\begin{abstract}
Background: Several studies have investigated the prevalence and risk factors of depression in subjects with obstructive sleep apnea syndrome. However, few studies have investigated the prevalence and risk factors for obstructive sleep apnea syndrome in major depression. The aim of this study was to examine the prevalence and risk factors of moderate to severe obstructive sleep apnea syndrome in a large sample of individuals with major depression.

Methods: Data from 703 individuals with major depression recruited from the research database of the sleep laboratory of the Erasme Hospital were analysed. An apnea-hypopnea index of $\geq 15$ events per hour was used as cut-off score for moderate to severe obstructive sleep apnea syndrome. Logistic regression analyses were conducted to examine clinical and demographic risk factors of moderate to severe obstructive sleep apnea syndrome in major depression.

Results: The prevalence of moderate to severe obstructive sleep apnea syndrome in major depression is $13.94 \%$. Multivariate logistic regression analysis revealed that male gender, snoring, excessive daytime sleepiness, lower insomnia complaint, presence of metabolic syndrome, age $\geq 50$ years, BMl $>30 \mathrm{~kg} / \mathrm{m}^{2}$, ferritin $>300 \mu \mathrm{g} / \mathrm{L}, \mathrm{CRP}>7 \mathrm{mg} / \mathrm{L}$ and duration of sleep $\geq 8 \mathrm{~h}$ were significant risk factors of moderate to severe obstructive sleep apnea syndrome in major depression.

Conclusion: Moderate to severe obstructive sleep apnea syndrome is a common pathology in major depression. The identification of these different risk factors advances a new perspective for more effective screening of moderate to severe obstructive sleep apnea syndrome in major depression.
\end{abstract}

Keywords: Major depression, Obstructive apnea syndrome, Prevalence, Risk factors

\section{Background}

Obstructive sleep apnea syndrome (OSA) is characterized by repetitive episodes of upper airway obstruction that occur during sleep and is usually associated with a reduction in blood oxygen saturation [1]. The clinical manifestations of OSA include witnessed apneas, snoring, choking/gasping episodes, excessive daytime sleepiness, non-restorative sleep, nocturia, sleep fragmentation/sleep maintenance insomnia, total sleep amount, morning headaches, loss of libido, irritability,

\footnotetext{
* Correspondence: matthieu.hein@erasme.ulb.ac.be

Department of Psychiatry and Sleep Laboratory, Erasme Hospital, Université Libre de Bruxelles, ULB, Route de Lennik, 808-1070, Anderlecht, Brussels, Belgium
}

(c) The Author(s). 2017 Open Access This article is distributed under the terms of the Creative Commons Attribution 4.0 International License (http://creativecommons.org/licenses/by/4.0/), which permits unrestricted use, distribution, and reproduction in any medium, provided you give appropriate credit to the original author(s) and the source, provide a link to the Creative Commons license, and indicate if changes were made. The Creative Commons Public Domain Dedication waiver (http://creativecommons.org/publicdomain/zero/1.0/) applies to the data made available in this article, unless otherwise stated.

and decreased concentration and memory [2]. Some of these symptoms are also present in mental pathologies, such as major depression, which may lead to an underdiagnosis of OSA in these subjects [3]. Both major depression and moderate to severe OSA (apnea-hypopnea index (AHI) $\geq 15 / \mathrm{h}$ ) [4] are associated with a higher risk of cardiovascular morbidity and mortality [5, 6], which justifies the need for effective treatment [7].

The co-occurrence of major depression and OSA may have a negative impact on the quality of life and is very frequent $[8,9]$. Indeed, in individuals with OSA, the prevalence of depressive affects may reach 63\% [10], whereas in individuals with major depression, the prevalence of OAS (AHI $\geq 5 / h$ ) was $36.3 \%$ [11]. However, few 
studies have investigated the prevalence of moderate to severe OSA in major depression. In one example, Ong et al. [12] found a prevalence of $39 \%$ of this syndrome in a population of 51 individuals with major depression, whereas in the general population, the prevalence is 1$14 \%$ (9-14\% of men and $2-7 \%$ of women) [13]. Thus, moderate to severe OSA appears to be more common in individuals with major depression than in the general population.

The classical OSA risk factors are age, male gender, body mass index (BMI), snoring, high blood pressure, metabolic syndrome, and sleep duration $\geq 8 \mathrm{~h}$ [14-17]. Although some of these OSA risk factors have been studied in major depression [11, 12, 18, 19], the majority have not been validated for moderate to severe OSA in the particular subpopulation of individuals with major depression.

Regarding alcohol consumption, smoking, benzodiazepines and Z-drugs use, data in the literature are contradictory concerning their potentially promoting effect in obstructive apneas [20-23]. Excessive daytime sleepiness is a common symptom in individuals with OSA [24] and may be measured by the use of the Epworth scale (ESS) [2]. Nevertheless, its use as a predictor of OSA is controversial in the general population $[25,26]$ and in major depression [18]. Additionally, even though the severity of depression is positively correlated with AHI [27], it does not predict the presence of OSA in major depression [12]. The use of these risk factors is therefore contradictory in the literature. Hence, it would be interesting to study such risk factors with a large sample of individuals with major depression to determine if, in this subpopulation, they are associated with a higher risk of moderate to severe OSA.

Furthermore, in major depression and OSA, there are arguments for the presence of chronic systemic inflammation resulting in higher levels of C-reactive protein (CRP) and ferritin [28-30]. In addition, OSA severity is correlated with the markers of this chronic inflammation [31, 32 ] that have never been studied as a predictor of OSA in either the general population or those with major depression. Therefore, it would be interesting to investigate if the presence of an inflammatory syndrome is associated with a higher risk of moderate to severe OSA in the subpopulation of major depressed individuals.

Our first objective is to investigate the actual prevalence of moderate to severe OSA in the particular subpopulation of individuals with major depression. Our second objective is to identify in this subpopulation, the specific risk factors of moderate to severe OSA. To achieve these goals, we recruited a large sample of major depressed individuals that we divided into a control group without moderate to severe OSA and a patient group with moderate to severe OSA. The aim of this approach is to enable health professionals who treat those with major depression to reference reliable data concerning this particular problem in this subpopulation and to better identify those at risk of moderate to severe OSA, a diagnosis currently made difficult by the existence of an overlap between symptoms of major depression and OSA.

\section{Methods}

\section{Population}

The 703 individuals with major depression were recruited from the database of the sleep laboratory of Erasme Hospital, which contains data for 3511 individuals who completed sleep laboratory monitoring in the years 20022014. In our study, we did not recruit subjects without major depression because our objective is to focus on the subpopulation of those with major depression where the existence of an overlap between the symptoms of major depression and OSA makes the diagnosis of this syndrome more difficult. Physicians specializing in sleep medicine referred these individuals to the sleep laboratory following an ambulatory consultation to evaluate their complaint of poor sleep and their depressive affects.

The inclusion criteria were age $\geq 18$ years and the presence of a major depressive episode meeting the diagnostic criteria of the Diagnostic and Statistical Manual of Mental Disorders fourth edition - Text Revision (DSM IV-TR) [33]. The exclusion criteria were presence of a psychiatric disorder other than major depression, presence of uncontrolled heavy somatic disease, presence of chronic pulmonary disease, presence of inflammatory or infectious disease, presence or history of cranial trauma, presence or history of central nervous system injury that could involve respiratory centres in the brain, presence or history of craniofacial or thoracic cavity malformations, presence of pregnancy, presence of OSA already known or course of treatment before sleep laboratory, presence of predominantly central apnea syndrome, presence of narcolepsy or primary hypersomnia, presence of parasomnia, and presence or history of substance abuse.

\section{Methods \\ Medical and psychiatric evaluation of participants}

All subjects upon admission to the sleep laboratory of Erasme Hospital had their medical records reviewed and a complete somatic check-up performed, including a blood test, electrocardiogram, a daytime electroencephalogram, urinalysis, and a chest X-ray (only for those over age 45). These steps allowed for a systematic diagnosis of potential somatic pathologies present in people admitted to our unit.

Metabolic syndrome was diagnosed when three or more of the following criteria were fulfilled: fasting 
blood glucose $\geq 100 \mathrm{mg} / \mathrm{dl}$ or receiving treatment for diabetes mellitus, blood pressure $\geq 135 / 85 \mathrm{mmHg}$ or receiving antihypertensive drug treatment, serum triglycerides $\geq 150 \mathrm{mg} / \mathrm{dl}$, serum HDL-Cholesterol $<40 \mathrm{mg} / \mathrm{dl}$ or receiving treatment for dyslipidemia, and waist circumference $\geq 94 \mathrm{~cm}$ for men or $\geq 80 \mathrm{~cm}$ for women $[34,35]$.

Patients also benefited on the day of admission from an appointment with a unit psychiatrist who potentially assigned psychiatric diagnoses per the DSM IV-TR criteria [33] to exclude subjects with psychiatric disorders other than major depression.

On admission, patients completed a series of selfquestionnaires to assess the severity of their subjective complaints of depression, poor sleep, and excessive daytime sleepiness as follows:

- The presence of depressive symptoms was investigated using the Beck Depression Inventory (BDI reduced to 13 items). This scale consists of 13 items that can be scored from 1 to 3 . The final score can vary from 0 to 39 . A final score of $0-4$ indicates an absence of depression, 5-7 a slight depression, $8-15$ a moderate depression, and $>16$ severe depression [36].

- Daytime sleepiness was investigated using the Epworth scale. This scale consists of eight questions that can be scored from 0 to 3 and assesses sleepiness during different daytime situations. The final score varies from 0 to 24 . A final score greater than 10 indicates excessive daytime sleepiness [37].

- The presence of insomnia symptoms was investigated using the Insomnia Severity Index (ISI). This index consists of seven questions that can be scored from 0 to 4 . The final score can vary from 0 to 28 . A score of $0-7$ indicates a lack of insomnia, 8-14 subclinical insomnia,15-21 moderate insomnia. and 22-28 severe insomnia [38].

To avoid missing values, individuals who did not respond fully to these questionnaires were not included in our study.

\section{Sleep evaluation and study}

A psychiatrist of the unit conducted a specific interview focused on sleep on the day of admission to complete an assessment of complaints related to sleep.

Participants stayed in a sleep laboratory for two nights, including a first night of habituation and a night of polysomnography from which the data were collected for analysis. The patients went to bed between 22:00-24:00 and got up between 6:00-8:00, following their usual schedule. During bedtime hours, the subjects were recumbent and the lights were turned off. Daytime naps were not permitted.
The polysomnographic recordings from our unit met the guidelines of the American Academy of Sleep Medicine (AASM) [39]. The applied polysomnographymontage was as follows: two electro-oculogram channels, three electroencephalogram channels (Fz-Ax, $\mathrm{Cz}-\mathrm{Ax}$, and $\mathrm{Oz}-\mathrm{Ax}$, where $\mathrm{Ax}$ was a contralateral mastoid reference), one submental electromyogram channel, electrocardiogram, thermistors to detect the oro-nasal airflow, finger pulse-oximetry, a microphone to record breathing sounds and snoring, piezoelectric sensors and leg movement electrodes. In addition, the applied polysomnography-montage also included strain gauges to measure thoracic and abdominal breathing. Polysomnographic recordings were visually scored by specialized technicians using AASM criteria [40] (inter-judge agreement score of $85 \%$ ).

Apneas were scored if the decrease in airflow was $\geq 90 \%$ for at least $10 \mathrm{~s}$ and hypopneas were scored if the decrease in airflow was $\geq 30 \%$ for at least $10 \mathrm{~s}$ with a decrease in oxygen saturation of $3 \%$ or followed by a micro-arousal [41]. AHI corresponds to the total number of apneas and hypopneas divided by period of sleep in hours. OSA was considered moderate to severe when AHI was $\geq 15 / h[4]$.

\section{Statistical analyses}

Statistical analyses were performed using Stata 14. The normal distribution of the data was verified using histograms, boxplots, and quantile-quantile plots, and the equality of variances was checked using the Levene's test.

We divided our sample of major depressed subjects into a control group without moderate to severe OSA and a patient group with moderate to severe OSA.

Categorical data were described with percentages and numbers, and continuous data were described with means and SD or median and P25-P75. Normally distributed variables were analysed with a $t$-test. A Wilcoxon test or chi [2] test were used on asymmetric distributed or dichotomous variables.

Univariate and multivariate binary logistic regression models were used to study the effects of risk factors on the occurrence of AHI $\geq 15$. Risk factor variables included ESS score (categorical: $\leq 10,>10$ ), ISI score (categorical: $<15, \geq 15$ ), BDI score (categorical: $<12, \geq 12$ ), BMI (categorical: $<25 \mathrm{~kg} / \mathrm{m}$ [2], $\geq 25 \&<30 \mathrm{~kg} / \mathrm{m}$ [2], $\geq 30 \mathrm{~kg} / \mathrm{m}^{2}$ ), age (categorical: $<50$ years, $\geq 50$ years), selfreported sleep duration (categorical: $<8 \mathrm{~h}, \geq 8 \mathrm{~h}$ ), ferritin (categorical: $\leq 300 \mu \mathrm{g} / \mathrm{L},>300 \mu \mathrm{g} / \mathrm{L}$ ), CRP (categorical: $\leq 7 \mathrm{mg} / \mathrm{L},>7 \mathrm{mg} / \mathrm{L}$ ), and as binary variables gender, snoring, metabolic syndrome, benzodiazepines use, Z-drugs use, antidepressants therapy, smoking, and alcohol consumption.

The automatic selection of risk factors in the model was performed by a stepwise backward method with an 
entry threshold of 0.05 and an exit threshold of 0.1 . The adequacy of the model was verified by the Hosmer and Lemeshow test and the specificity of the model by Link Test. The numbers of subjects by risk factors, outliers, and collinearity between risk factors that may cause problems, have also been verified.

A $p$-value of less than 0.05 was considered significant.

\section{Results}

\section{Demographic data (Table 1)}

Male gender, snoring, metabolic syndrome, Z-drugs use and alcohol consumption are more frequent in subjects with AHI $\geq 15 / \mathrm{h}$. These subjects also present an age/ BMI/ESS score greater and BDI/ISI score lower than the subjects with AHI $<15 / \mathrm{h}$. Markers of chronic inflammation, such as CRP and ferritin, are higher in moderate to severe OSA. There was no significant difference in benzodiazepines use, antidepressants therapy, smoking, and duration of sleep $\geq 8 \mathrm{~h}$.

\section{Prevalence of moderate to severe OSA in major depression (Table 1)}

The prevalence of moderate to severe OSA in our sample of 703 individuals with major depression is 13.94\% $(n=98)$.

\section{Univariate analysis (Table 2)}

Male gender, snoring, ESS score $>10$, ISI score $<15$, metabolic syndrome, Z-drugs use, alcohol consumption, age $\geq 50$ years, BMI $\geq 25 \&<30 \mathrm{~kg} / \mathrm{m}^{2}, \mathrm{BMI}>30 \mathrm{~kg} / \mathrm{m}^{2}$, and ferritin $>300 \mu \mathrm{g} / \mathrm{L}$ were associated with an increased risk of moderate to severe OSA in major depression.

\section{Multivariate analysis (Table 3)}

In major depression, risk factors associated significantly with an increased risk of moderate to severe OSA and obtained by the method of automatic selection (stepwise backward) were male gender, snoring, ESS score $>10$, ISI score $<15$, metabolic syndrome, age $\geq 50$ years, BMI $>30 \mathrm{~kg} / \mathrm{m}^{2}$, ferritin $>300 \mu \mathrm{g} / \mathrm{L}, \mathrm{CRP}>7 \mathrm{mg} / \mathrm{L}$, and duration of sleep $\geq 8 \mathrm{~h}$.

\section{Discussion}

In our sample of individuals with major depression, we demonstrated a prevalence of moderate to severe OSA of $13.94 \%$, which highlights the importance of this problem to the healthcare professionals treating this particular subpopulation of patients. This prevalence is similar to that of the general population [13], but less than that of $39 \%$ of the study of Ong et al. [12] However, in this study, the sample was relatively small and to be included, these individuals had to present with insomnia meeting the diagnostic criteria of DSM-IV-TR [33]. This diagnostic criteria included difficulty initiating or maintaining sleep, non-restorative sleep, clinically significant distress, or impairment in social, occupational, or other important areas of functioning; all of which are also symptoms of OSA [2] and may result in greater recruitment of patients with major depression and moderate to severe OSA and could explain the difference in prevalence within our study. Moreover, although the prevalence of moderate to severe OSA in major depression appears to be similar to that of the general population as indicated by our results, the existence of an overlap between the symptoms of major depression and OSA [42] as well as non-compliance with medical treatment in individuals with major depression [43] may lead to the under-diagnosis of moderate to severe OSA in major depression [3]. However, moderate to severe OSA is associated with increased cardiovascular morbidity and mortality [44], which justifies the implementation of effective treatment [45]. Therefore, in individuals with major depression, it is important to identify the specific risk factors for moderate to severe OSA to enhance the detection and management of this syndrome and reduce cardiovascular complications for these individuals.

As in the general population [14], we found that male gender, age $\geq 50$ years, and BMI $\geq 30 \mathrm{~kg} / \mathrm{m}^{2}$ are risk factors for moderate to severe OSA in major depression, which seems to confirm the results of Ong et al. [12] Furthermore, although snoring is a risk factor for mild to severe OSA in major depression [18], it has not been studied specifically for moderate to severe OSA. Nevertheless, in our study, we have demonstrated that similar to the general population [14], snoring is also a risk factor for moderate to severe OSA in individuals with major depression. We therefore confirmed with a large sample that the classical risk factors for moderate to severe OSA in the general population are applicable to the subpopulation of individuals with major depression, which seems to confirm the results of preliminary studies involving smaller samples of individuals with major depression $[12,18]$.

In the general population, there is a special relationship between OSA and metabolic syndrome. Indeed, subjects with a metabolic syndrome have a higher risk of severe OSA [17], and individuals with moderate to severe OSA have a higher risk of metabolic syndrome [46, 47]. In addition, the prevalence of metabolic syndrome increases with the severity of OSA [48]. However, in major depression, no studies have investigated the relationship between OSA and metabolic syndrome, which are two syndromes that frequently present in individuals with major depression [11, 49]. Another risk factor for moderate to severe OSA found in the general population, but not studied in major depression, is sleep duration $\geq 8 \mathrm{~h}$ [16]. However, in our study, we demonstrated that as in the general population, metabolic syndrome 
Table 1 Sample description $(n=703)$

\begin{tabular}{|c|c|c|c|c|c|c|}
\hline Variables & & Categories & $\%$ & Group AHI $<15 / \mathrm{h}$ & Group AHI $\geq 15 / h$ & $P$-value $\mathrm{Chi}^{2}$ \\
\hline \multirow[t]{2}{*}{ Gender } & & Male $(n=320)$ & $45.52 \%$ & $38.68 \%$ & $87.76 \%$ & $<0.001$ \\
\hline & & Female $(n=383)$ & $54.48 \%$ & $61.32 \%$ & $12.24 \%$ & \\
\hline \multirow{2}{*}{\multicolumn{2}{|c|}{ Snoring }} & No $(n=342)$ & $48.65 \%$ & $53.22 \%$ & $20.41 \%$ & $<0.001$ \\
\hline & & Yes $(n=361)$ & $51.35 \%$ & $46.78 \%$ & $79.59 \%$ & \\
\hline \multirow{2}{*}{\multicolumn{2}{|c|}{ Metabolic syndrome }} & No $(n=636)$ & $90.47 \%$ & $93.72 \%$ & $70.41 \%$ & $<0.001$ \\
\hline & & Yes $(n=67)$ & $9.53 \%$ & $6.28 \%$ & $29.59 \%$ & \\
\hline \multirow{2}{*}{\multicolumn{2}{|c|}{ Benzodiazepines use }} & No $(n=534)$ & $75.96 \%$ & $76.03 \%$ & $75.51 \%$ & 0.911 \\
\hline & & Yes $(n=169)$ & $24.04 \%$ & $23.97 \%$ & $24.49 \%$ & \\
\hline \multirow{2}{*}{\multicolumn{2}{|c|}{ Z-drugs use }} & No $(n=650)$ & $92.46 \%$ & $91.57 \%$ & $97.96 \%$ & 0.026 \\
\hline & & Yes $(n=53)$ & $7.54 \%$ & $8.43 \%$ & $2.04 \%$ & \\
\hline \multirow{2}{*}{\multicolumn{2}{|c|}{ Antidepressant therapy }} & No $(n=408)$ & $58.04 \%$ & $58.51 \%$ & $55.10 \%$ & 0.526 \\
\hline & & Yes $(n=295)$ & $41.96 \%$ & $41.49 \%$ & $44.90 \%$ & \\
\hline \multirow{2}{*}{\multicolumn{2}{|c|}{ Smoking }} & No $(n=528)$ & $75.11 \%$ & $74.21 \%$ & $80.61 \%$ & 0.174 \\
\hline & & Yes $(n=175)$ & $24.89 \%$ & $25.79 \%$ & $19.39 \%$ & \\
\hline \multirow[t]{3}{*}{ Alcohol } & & No $(n=548)$ & $77.95 \%$ & $79.50 \%$ & $68.37 \%$ & 0.014 \\
\hline & & Yes $(n=155)$ & $22.05 \%$ & $20.50 \%$ & $31.63 \%$ & \\
\hline & Mean $\pm S D$ & & & & & t-test \\
\hline \multirow[t]{4}{*}{$\mathrm{BMI}\left(\mathrm{kg} / \mathrm{m}^{2}\right)$} & $27.32 \pm 6.31$ & & & $26.69 \pm 6.14$ & $31.24 \pm 5.94$ & $<0.001$ \\
\hline & & $<25(n=300)$ & $42.67 \%$ & $47.60 \%$ & $12.25 \%$ & \\
\hline & & $\geq 25 \&<30(n=191)$ & $27.17 \%$ & $26.45 \%$ & $31.63 \%$ & \\
\hline & & $\geq 30(n=212)$ & $30.16 \%$ & $25.95 \%$ & $56.12 \%$ & \\
\hline \multirow[t]{3}{*}{ Age (years) } & $44.96 \pm 12.29$ & & & $43.55 \pm 11.95$ & $53.66 \pm 10.68$ & $<0.001$ \\
\hline & & $<50(n=463)$ & $65.86 \%$ & $70.91 \%$ & $34.69 \%$ & \\
\hline & & $\geq 50(n=240)$ & $34.14 \%$ & $29.09 \%$ & $65.31 \%$ & \\
\hline \multirow[t]{4}{*}{ Sleep duration (hour) } & $8.26 \pm 0.89$ & & & $8.26 \pm 0.88$ & $8.25 \pm 0.95$ & 0.917 \\
\hline & & $<8(n=394)$ & $56.05 \%$ & $57.19 \%$ & $48.98 \%$ & \\
\hline & & $\geq 8(n=309)$ & $43.95 \%$ & $42.81 \%$ & $51.02 \%$ & \\
\hline & Median (P25-P75) & & & & & Wilcoxon test \\
\hline \multirow[t]{3}{*}{ Ferritin $(\mu \mathrm{g} / \mathrm{L})$} & $102(48-209)$ & & & $89(42-184)$ & $261.5(134-406)$ & $<0.001$ \\
\hline & & $<300(n=606)$ & $86.20 \%$ & $90.74 \%$ & $58.16 \%$ & \\
\hline & & $\geq 300(n=97)$ & $13.80 \%$ & $9.26 \%$ & $41.84 \%$ & \\
\hline \multirow[t]{3}{*}{ CRP (mg/L) } & $1.6(0.9-3.5)$ & & & $1.5(0.87-3.4)$ & $1.95(1-3.7)$ & 0.041 \\
\hline & & $\leq 7(n=643)$ & $91.47 \%$ & $92.30 \%$ & $86.73 \%$ & \\
\hline & & $>7(n=60)$ & $8.53 \%$ & $7.7 \%$ & $13.27 \%$ & \\
\hline \multirow[t]{3}{*}{$\mathrm{BDI}$} & $12(9-16)$ & & & $12(10-16)$ & $11(9-14)$ & 0.025 \\
\hline & & $<12(n=331)$ & $47.08 \%$ & $45.79 \%$ & $55.10 \%$ & \\
\hline & & $\geq 12(n=372)$ & $52.92 \%$ & $54.21 \%$ & $44.90 \%$ & \\
\hline \multirow[t]{3}{*}{$|S|$} & $18(15-21)$ & & & $19(16-22)$ & $15(12-19)$ & $<0.001$ \\
\hline & & $\geq 15(n=548)$ & $77.95 \%$ & $81.49 \%$ & $96.12 \%$ & \\
\hline & & $<15(n=155)$ & $22.05 \%$ & $18.51 \%$ & $3.88 \%$ & \\
\hline \multirow[t]{3}{*}{ Epworth } & $11(7-14)$ & & & $10(6-14)$ & $11.5(9-15)$ & 0.001 \\
\hline & & $\leq 10(n=346)$ & $49.22 \%$ & $51.24 \%$ & $36.73 \%$ & \\
\hline & & $>10(n=357)$ & $50.78 \%$ & $48.76 \%$ & $63.27 \%$ & \\
\hline \multirow[t]{2}{*}{$\mathrm{AHI}$} & $2(1-7)$ & $<15 / h(n=605)$ & $86.06 \%$ & & & \\
\hline & & $\geq 15 / h(n=98)$ & $13.94 \%$ & & & \\
\hline
\end{tabular}


Table 2 Univariate analysis $(n=703)$

\begin{tabular}{|c|c|c|c|c|}
\hline Variables & $\begin{array}{l}\% \mathrm{AHI} \\
<15 / \mathrm{h}\end{array}$ & $\begin{array}{l}\% \mathrm{AHI} \\
\geq 15 / \mathrm{h}\end{array}$ & OR (IC 95\%) & $P$-value \\
\hline Gender & & & & $<0.001$ \\
\hline Male & $73.12 \%$ & $26.88 \%$ & $\begin{array}{l}11.36 \\
\text { (6.08 to 21.24) }\end{array}$ & \\
\hline Female & $96.87 \%$ & $3.13 \%$ & 1 & \\
\hline Snoring & & & & $<0.001$ \\
\hline Yes & $78.39 \%$ & $21.61 \%$ & $\begin{array}{l}4.44 \\
\text { (2.65 to } 7.44)\end{array}$ & \\
\hline No & $94.15 \%$ & $5.85 \%$ & 1 & \\
\hline Epworth & & & & 0.008 \\
\hline$\leq 10$ & $89.60 \%$ & $10.40 \%$ & 1 & \\
\hline$>10$ & $82.63 \%$ & $17.37 \%$ & $\begin{array}{l}1.81 \\
\text { (1.16 to } 2.81)\end{array}$ & \\
\hline$|S|$ & & & & $<0.001$ \\
\hline$\geq 15$ & $89.96 \%$ & $10.04 \%$ & 1 & \\
\hline$<15$ & $72.26 \%$ & $27.74 \%$ & $\begin{array}{l}3.44 \\
(2.20 \text { to } 5.39)\end{array}$ & \\
\hline BDI & & & & 0.088 \\
\hline$<12$ & $83.69 \%$ & $16.31 \%$ & 1 & \\
\hline$\geq 12$ & $88.17 \%$ & $11.83 \%$ & $\begin{array}{l}0.69 \\
(0.45 \text { to } 1.06)\end{array}$ & \\
\hline Metabolic syndrome & & & & $<0.001$ \\
\hline Yes & $56.72 \%$ & $43.28 \%$ & $\begin{array}{l}6.27 \\
\text { (3.64 to } 10.81)\end{array}$ & \\
\hline No & $89.15 \%$ & $10.85 \%$ & 1 & \\
\hline Benzodiazepines use & & & & 0.911 \\
\hline Yes & $85.80 \%$ & $14.20 \%$ & $\begin{array}{l}1.03 \\
(0.63 \text { to } 1.69)\end{array}$ & \\
\hline No & $86.14 \%$ & $13.86 \%$ & 1 & \\
\hline Z-drugs use & & & & 0.042 \\
\hline Yes & $96.23 \%$ & $3.77 \%$ & $\begin{array}{l}0.23 \\
(0.05 \text { to } 0.95)\end{array}$ & \\
\hline No & $85.23 \%$ & $14.77 \%$ & 1 & \\
\hline Antidepressant therapy & & & & 0.526 \\
\hline Yes & $85.08 \%$ & $14.92 \%$ & $\begin{array}{l}1.15 \\
(0.75 \text { to } 1.77)\end{array}$ & \\
\hline No & $86.76 \%$ & $13.24 \%$ & 1 & \\
\hline Smoking & & & & 0.176 \\
\hline Yes & $89.14 \%$ & $10.86 \%$ & $\begin{array}{l}0.69 \\
(0.41 \text { to } 1.18)\end{array}$ & \\
\hline No & $85.04 \%$ & $14.96 \%$ & 1 & \\
\hline Alcohol & & & & 0.015 \\
\hline Yes & $80 \%$ & $20 \%$ & $\begin{array}{l}1.79 \\
(1.12 \text { to } 2.87)\end{array}$ & \\
\hline No & $87.77 \%$ & $12.23 \%$ & 1 & \\
\hline BMI $\left(\mathrm{kg} / \mathrm{m}^{2}\right)$ & & & & $<0.001$ \\
\hline$<25$ & $96 \%$ & $4 \%$ & 1 & \\
\hline$\geq 25 \&<30$ & $83.77 \%$ & $16.23 \%$ & $\begin{array}{l}4.65 \\
(2.32 \text { to } 9.31)\end{array}$ & \\
\hline
\end{tabular}

Table 2 Univariate analysis $(n=703)$ (Continued)

\begin{tabular}{|c|c|c|c|c|}
\hline Variables & $\begin{array}{l}\% \mathrm{AHI} \\
<15 / \mathrm{h}\end{array}$ & $\begin{array}{l}\% \mathrm{AHI} \\
\geq 15 / \mathrm{h}\end{array}$ & OR (IC 95\%) & $P$-value \\
\hline$\geq 30$ & $74.06 \%$ & $25.94 \%$ & $\begin{array}{l}8.41 \\
\text { (4.37 to } 16.17)\end{array}$ & \\
\hline Age (years) & & & & $<0.001$ \\
\hline$<50$ & $92.66 \%$ & $7.34 \%$ & 1 & \\
\hline$\geq 50$ & $73.33 \%$ & $26.67 \%$ & $\begin{array}{l}4.59 \\
(2.92 \text { to } 7.21)\end{array}$ & \\
\hline Sleep duration (hour) & & & & 0.130 \\
\hline$<8$ & $87.82 \%$ & $12.18 \%$ & 1 & \\
\hline$\geq 8$ & $83.82 \%$ & $16.18 \%$ & $\begin{array}{l}1.39 \\
(0.91 \text { to } 2.13)\end{array}$ & \\
\hline Ferritin $(\mu \mathrm{g} / \mathrm{L})$ & & & & $<0.001$ \\
\hline$<300$ & $90.59 \%$ & $9.41 \%$ & 1 & \\
\hline$\geq 300$ & $57.73 \%$ & $42.27 \%$ & $\begin{array}{l}7.05 \\
\text { (4.34 to } 11.47)\end{array}$ & \\
\hline CRP (mg/L) & & & & 0.074 \\
\hline$\leq 7$ & $86.78 \%$ & $13.22 \%$ & 1 & \\
\hline$>7$ & $78.33 \%$ & $21.67 \%$ & $\begin{array}{l}1.82 \\
(0.94 \text { to } 3.50)\end{array}$ & \\
\hline
\end{tabular}

$B M I$ Body Mass Index, ISI Insomnia Severity Index, BDI Beck Depression Inventory, AHI Apnea-Hypopnea Index

and duration of sleep $\geq 8 \mathrm{~h}$ are also risk factors for moderate to severe OSA in the particular subpopulation of individuals with major depression.

Despite two meta-analyses $[25,26]$, data in the literature on the use of excessive daytime sleepiness measured by ESS as a predictor of moderate to severe OSA in the general population are contradictory. Yet, in mental pathologies, including major depression, the use of ESS as a risk factor for moderate to severe OSA seems to not be recommended, as demonstrated in the study of Nikolakaros et al. [18] However, in this study, the sample size was small and it did not consist solely of individuals with major depression. In OSA, there is a particular relationship between daytime sleepiness measured by ESS and major depression. Indeed, in subjects with OSA, the presence of excessive daytime sleepiness is associated with a greater risk of depression [50], whereas depressive symptoms contribute significantly to excessive daytime sleepiness [51]. These elements allow better understanding why we have shown that excessive daytime sleepiness is a risk factor of moderate to severe OSA in major depression. Although some studies show a positive correlation between AHI and the severity of depression $[27,52]$, we have demonstrated a finding similar to Ong et al. [10] where subjects with an AHI $\geq 15 / h$ had a lower self-reported severity of depression than subjects with $\mathrm{AHI}<15 / \mathrm{h}$, and that the self-reported severity of depression is not a risk factor for moderate to severe OSA in major depression. In addition, Bjorvatn et al. [53] have 
Table 3 Summary of logistic regression for screening variables predicting $\mathrm{AHI} \geq 15 / \mathrm{h}$ in major depression $(\mathrm{n}=703)$

\begin{tabular}{|c|c|c|}
\hline Variables & Adjusted OR (IC 95\%) & $P$-value \\
\hline Gender & & $<0.001$ \\
\hline Male & $10.71(5.02$ to 22.86$)$ & \\
\hline Female & 1 & \\
\hline Snoring & & 0.007 \\
\hline Yes & 2.36 (1.27 to 4.39$)$ & \\
\hline No & 1 & \\
\hline Epworth & & 0.002 \\
\hline$\leq 10$ & 1 & \\
\hline$>10$ & 2.45 (1.39 to 4.35$)$ & \\
\hline Ferritin $(\mu \mathrm{g} / \mathrm{L})$ & & 0.009 \\
\hline$<300$ & 1 & \\
\hline$\geq 300$ & 2.27 (1.22 to 4.20$)$ & \\
\hline CRP (mg/L) & & 0.039 \\
\hline$\leq 7$ & 1 & \\
\hline$>7$ & 2.76 (1.05 to 7.23$)$ & \\
\hline BMI $\left(\mathrm{kg} / \mathrm{m}^{2}\right)$ & & 0.019 \\
\hline$<25$ & 1 & \\
\hline$\geq 25 \&<30$ & 2.06 (0.93 to 4.59$)$ & \\
\hline$\geq 30$ & 2.62 (1.20 to 5.73$)$ & \\
\hline Age (years) & & $<0.001$ \\
\hline$<50$ & 1 & \\
\hline$\geq 50$ & 3.42 (1.94 to 6.02$)$ & \\
\hline$|S|$ & & $<0.001$ \\
\hline$<15$ & 3.51 (1.96 to 6.29$)$ & \\
\hline$\geq 15$ & 1 & \\
\hline Metabolic syndrome & & 0.015 \\
\hline Yes & 2.45 (1.19 to 5.02$)$ & \\
\hline No & 1 & \\
\hline Sleep duration (hour) & & 0.039 \\
\hline$<8$ & 1 & \\
\hline$\geq 8$ & 1.77 (1.03 to 3.05$)$ & \\
\hline
\end{tabular}

Not included in the model because not significant: BDI, benzodiazepines, Z-drugs, antidepressants, smoking and alcohol

Adequacy of model: Hosmer-Lemeshow chi2 $(p=0.863)$

Specificity of model: Linktest (linear component $p<0.001$ and nonlinear component $p=0.638$ )

$B M I$ Body Mass Index, ISI Insomnia Severity Index, BDI Beck Depression Inventory, AHI Apnea-Hypopnea Index

shown that the prevalence of insomnia complaints decreased when the severity of OSA increased, which enhances the understanding of our results. Indeed, in our study, we have shown that individuals with major depression and lower self-reported complaints of insomnia had a greater risk of moderate to severe OSA. Therefore, in the subpopulation of those with major depression, excessive daytime sleepiness and lower insomnia complaints are risk factors for moderate to severe OSA, unlike the self-reported severity of depression.

In OSA and major depression, there are arguments in favour of chronic inflammation, which may be correlated with the severity of OSA $[31,32]$ and which may result in higher plasma levels of CRP and ferritin [54-56]. Despite the special relationship between chronic inflammation and depression/OSA, plasma CRP and ferritin levels have never been studied as a risk factor for OSA in the general population or individuals with major depression. However, in our study, we found that the presence of chronic inflammation in a subpopulation of individuals with major depression was a risk factor for moderate to severe OSA, which advances new perspectives in understanding the relationship between OSA and major depression.

Antidepressants may partially improve OSA by suppressing REM sleep and increasing upper airway tone [57]. However, in our study, we demonstrated that antidepressants are not a risk or protector factor for moderate to severe OSA in individuals with major depression. This can be explained by the fact we did not distinguish between the different classes of antidepressants, which may possibly mask the protective or deleterious effect of certain molecules on respiration. We found that benzodiazepines and Z-drugs are not risk factors for moderate to severe OSA, which seems to confirm the results of the meta-analysis of Mason et al. [23] However, we excluded subjects with dependence and therefore an overconsumption of these molecules. Benzodiazepines and Z-drugs are generally safe at a low dose for nocturnal breathing, but at high doses, they may cause or aggravate sleep apnea in some more fragile patients [57]. Thus, taking benzodiazepines and Z-drugs at a recommended dose, especially for the subpopulation of individuals with major depression, is not a risk factor for moderate to severe OSA.

The role of smoking in the occurrence of obstructive apnea is controversial in the literature $[58,59]$. It would appear that nicotine would decrease the resistance of the upper airways with a consequent reduction of the risk of OSA, whereas in case of withdrawal, this resistance would become more important and would cause a greater risk of OSA [60]. Nevertheless, a protective effect of smoking for OSA has yet to be investigated. In our study, we found that smoking is not a risk factor for moderate to severe OSA in the subpopulation of major depressed subjects. This may be explained by the fact that we included only active smokers who did not have nicotine withdrawal during their sleep laboratory. Further, in the literature, alcohol is a recognized risk factor for OSA. In fact, it induces a decrease in the tone of the upper airway muscles, which may increase the frequency and the severity of obstructive apnea in subjects with 
OSA, especially during the first hours of sleep [61]. Similarly, we demonstrated that alcohol is not a risk factor for moderate to severe OSA in the subpopulation of individuals with major depression. This difference from the literature can be explained by the fact that none of the subjects included in our study had alcohol dependence and thus could stop their habitual consumption of alcohol during the sleep laboratory without consequence and avoid its deleterious effects on nocturnal breathing.

In the future, prospective studies should be conducted with the subpopulation of individuals with major depression to validate the risk factors of moderate to severe OSA highlighted in our study. In addition, it would be useful to develop a score from these risk factors to better identify those at risk of moderate to severe OSA.

\section{Limitations}

The results obtained in our study come from retrospective data that, even if they have been encoded in a systematic manner, cannot be verified directly with the subject in most cases, which means that our results need to be replicated in prospective studies. Further, we used an automatic selection of risk factors by a stepwise backward method, which presents some limitations that can be consulted on http://www.stata.com/support/faqs/statistics/stepwise-regression-problems. Moreover, we focused only on moderate to severe OSA, which means that our results cannot be generalized to other breathing disorders during sleep, such as central apnea syndrome. As we have included only patients with major depression and without other psychiatric comorbidities, our results are not generalizable to all individuals with major depression or other psychiatric disorders.

\section{Conclusion}

We demonstrated in a large sample of individuals with major depression that the prevalence of moderate to severe OSA was $13.94 \%$, and that the classical risk factors for moderate to severe OSA (male gender, age $\geq 50$ years, BMI $\geq 30 \mathrm{~kg} / \mathrm{m}^{2}$, and snoring) were applicable this particular subpopulation. We also found that the presence of metabolic syndrome, sleep duration $\geq 8 \mathrm{~h}$, excessive daytime sleepiness, lower insomnia complaints, and markers of chronic inflammation (CRP and ferritin) were also risk factors for this syndrome in the subpopulation of individuals with major depression, unlike selfreported severity of depression, antidepressant therapy, smoking, alcohol consumption, or benzodiazepines and Z-drugs use.

\section{Highlights}

- The prevalence of moderate to severe OSA in major depression is $13.94 \%$.
- Male gender, age $\geq 50$ years, $\mathrm{BMI} \geq 30 \mathrm{~kg} / \mathrm{m}^{2}$, snoring, presence of metabolic syndrome, sleep duration $\geq 8 \mathrm{~h}$, excessive daytime sleepiness, lower insomnia complaints and markers of chronic inflammation (CRP and ferritin) were risk factors for moderate to severe OAS in major depression.

- These risk factors open up a new perspective for more effective screening of moderate to severe OSA in major depression.

\section{Abbreviations}

AHI: Apnea-hypopnea index; BDI: Beck depression inventory; BMI: Body mass index; CRP: C-reactive protein; DSM IV-TR: Diagnostic and Statistical Manual of Mental Disorders fourth edition - Text Revision; ESS: Epworth scale; ISI: Insomnia severity index; OSA: Obstructive sleep apnea syndrome

\section{Acknowledgements}

I want to thank Christelle Bouchart (MD) for her support and the sleep laboratory team from the Erasmus Hospital for technical support.

\section{Funding}

This research did not receive any specific grant from funding agencies in the public, commercial, or not-for-profit sectors.

\section{Availability of data and materials}

The datasets used and/or analyzed during the current study are available from the corresponding author on reasonable request.

\section{Authors' contributions}

$\mathrm{MH}$ : principal investigator of the study with active participation in the encoding of data, statistical analysis, interpretation of results and writing of the article. JL: Active participation in the extraction and calculation of data from polysomnography for the realization of the database. GL: Support in the English translation of the manuscript and supervised the research work as a thesis promoter. PL: Support in drafting the manuscript and supervision of the research work as a thesis

co-promoter. PH: Support in drafting the manuscript and supervision of research work as a member of the accompanying thesis committee. All authors read and approved the final manuscript.

\section{Ethics approval and consent to participate}

This research protocol was approved by the Hospital and Medical School Ethics Committee of the Erasme Hospital (Brussels University Clinics) (Erasme Reference: P2017/119). At Erasme Hospital, all patients are informed that their data could be used retrospectively for scientific research. If patients do not wish for their data to be used, they must inform the hospital, at which time, this directive is indicated in their medical records, and any future use of their data is prohibited.

Consent for publication

Not applicable.

\section{Competing interests}

The authors declare that they have no competing interests.

\section{Publisher's Note}

Springer Nature remains neutral with regard to jurisdictional claims in published maps and institutional affiliations.

Received: 3 March 2017 Accepted: 24 November 2017

Published online: 04 December 2017

References

1. American Sleep Disorders Association, Diagnostic Classification Steering Committee. International classification of sleep disorders: diagnostic and coding manual, ICSD-R. Westchester: American Academy of Sleep Medicine; 2005.

2. Epstein LJ, Kristo D, Strollo PJ Jr, Friedman N, Malhotra A, Patil SP, Ramar K, Rogers R, Schwab RJ, Weaver EM, Weinstein MD. Adult obstructive sleep apnea task force of the American Academy of sleep medicine. Clinical 
guideline for the evaluation, management and long-term care of obstructive sleep apnea in adults. J Clin Sleep Med. 2009:5(3):263-76.

3. Naqvi HA, Wang D, Glozier N, Grunstein RR. Sleep-disordered breathing and psychiatric disorders. Curr Psychiatry Rep. 2014;16(12):519.

4. Fleetham J, Ayas N, Bradley D, Ferguson K, Fitzpatrick M, George C, Hanly P, Hill F, Kimoff J, Kryger M, Morrison D, Series F, Tsai W, CTS Sleep Disordered Breathing Committee. Canadian thoracic society guidelines:diagnosis and treatment of sleep disordered breathing in adults. Can Respir J. 2006;13(7):387-92.

5. Van der Kooy K, van Hout H, Marwijk H, Marten H, Stehouwer C, Beekman A. Depression and the risk for cardiovascular diseases: systematic review and meta-analysis. Int J Geriatr Psychiatry. 2007;22(7):613-26.

6. Kendzerska T, Gershon AS, Hawker G, Leung RS, Tomlinson G. Obstructive sleep apnea and risk of cardiovascular events and all-cause mortality: a decade-long historical cohort study. PLoS Med. 2014;11(2):e1001599.

7. Trakada G, Economou NT, Nena E, Trakada A, Zarogoulidis P, Steiropoulos PA. Health-economic analysis of diagnosis and treatment of obstructive sleep apnea with continuous positive airway pressure in relation to cardiovascular disease. The Greek experience. Sleep Breath. 2015;19(2):467-72.

8. Yosunkaya S, Kutlu R, Cihan FG. Evaluation of depression and quality of life in patients with obstructive sleep apnea syndrome. Niger I Clin Pract. 2016:19(5):573-9.

9. Altintaş A, Soylu A, Yegin Y, Çelik M, Kaya KH. Impact of Laryngopharyngeal reflux on the levels of depression and anxiety in patients with obstructive sleep apnea syndrome. J Craniofac Surg. 2017;28(2):e121-4.

10. Saunamäki T, Jehkonen M. Depression and anxiety in obstructive sleep apnea syndrome: a review. Acta Neurol Scand. 2007;116(5):277-88.

11. Stubbs B, Vancampfort D, Veronese N, Solmi M, Gaughran F, Manu P, Rosenbaum S, De Hert M, Fornaro M. The prevalence and predictors of obstructive sleep apnea in major depressive disorder, bipolar disorder and schizophrenia: a systematic review and meta-analysis. J Affect Disord. 2016;197:259-67.

12. Ong JC, Gress JL, San Pedro-Salcedo MG, Manber R. Frequency and predictors of obstructive sleep apnea among individuals with major depressive disorder and insomnia. J Psychosom Res. 2009;67(2):135-41.

13. Young T, Peppard PE, Gottlieb DJ. Epidemiology of obstructive sleep apnea: a population health perspective. Am J Respir Crit Care Med. 2002;165(9): 1217-39.

14. Young T, Shahar E, Nieto FJ, Redline S, Newman AB, Gottlieb DJ, Walsleben $J A$, Finn L, Enright P, Samet JM, Sleep Heart Health Study Research Group. Predictors of sleep-disordered breathing in community-dwelling adults: the sleep heart health study. Arch Intern Med. 2002;162(8):893-900.

15. Cairns A, Poulos G, Bogan R. Sex differences in sleep apnea predictors and outcomes from home sleep apnea testing. Nat Sci Sleep. 2016;8:197-205.

16. Broström A, Sunnergren O, Årestedt K, Johansson P, Ulander M, Riegel B, Svanborg E. Factors associated with undiagnosed obstructive sleep apnoea in hypertensive primary care patients. Scand J Prim Health Care. 2012;30(2): 107-13.

17. Kawada T, Otsuka T, Nakamura T, Kon Y. Relationship between sleepdisordered breathing and metabolic syndrome after adjustment with cardiovascular risk factors. Diabetes Metab Syndr. 2016;10(2):92-5.

18. Nikolakaros G, Virtanen I, Markkula J, Vahlberg T, Saaresranta T. Obstructive sleep apnea in psychiatric outpatients. A clinic-based study. J Psychiatr Res. 2015;69:126-34.

19. Guichard K, Marti-Soler H, Micoulaud-Franchi JA, Philip P, Marques-Vidal P, Vollenweider P, Waeber G, Preisig M, Haba-Rubio J, Heinzer R. The NoSAS score: a new and simple screening tool for obstructive sleep apnea syndrome in depressive disorder. J Affect Disord. 2017;227:136-40

20. Punjabi NM. The epidemiology of adult obstructive sleep apnea. Proc Am Thorac Soc. 2008;5(2):136-43.

21. Gupta MA, Simpson FC. Obstructive sleep apnea and psychiatric disorders: a systematic review. J Clin Sleep Med. 2015;11(2):165-75.

22. Gharibeh T, Mehra R. Obstructive sleep apnea syndrome: natural history, diagnosis, and emerging treatment options. Nat Sci Sleep. 2010;2:233-55.

23. Mason M, Cates CJ, Smith I. Effects of opioid, hypnotic and sedating medications on sleep-disordered breathing in adults with obstructive sleep apnea. Cochrane Database Syst Rev. 2015;7:CD011090.

24. Ulasli SS, Gunay E, Koyuncu T, Akar O, Halici B, Ulu S, Unlu M. Predictive value of Berlin questionnaire and Epworth sleepiness scale for obstructive sleep apnea in a sleep clinic population. Clin Respir J. 2014;8(3):292-6.

25. Ramachandran SK, Josephs LA. A meta-analysis of clinical screening tests for obstructive sleep apnea. Anesthesiology. 2009;110(4):928-39.
26. Chiu HY, Chen PY, Chuang LP, Chen NH, YK T, Hsieh YJ, Wang YC, Guilleminault C. Diagnostic accuracy of the Berlin questionnaire, STOPBANG, STOP, and Epworth sleepiness scale in detecting obstructive sleep apnea: a bivariate meta-analysis. Sleep Med Rev. 2016;5:1-14.

27. Aloia MS, Arnedt JT, Smith L, Skrekas J, Stanchina M, Millman RP. Examining the construct of depression in obstructive sleep apnea syndrome. Sleep Med. 2005;6(2):115-21.

28. Maes M, Van de Vyvere J, Vandoolaeghe E, Bril T, Demedts P, Wauters A, Neels $\mathrm{H}$. Alterations in iron metabolism and the erythron in major depression: further evidence for a chronic inflammatory process. J Affect Disord. 1996;40(1-2):23-33.

29. Einvik G, Hrubos-Strøm H, Randby A, Nordhus $H$, Somers VK, Omland T, Dammen T. Major depressive disorder, anxiety disorders, and cardiac biomarkers in subjects at high risk of obstructive sleep apnea. Psychosom Med. 2011;73(5):378-84

30. Yardim-Akaydin S, Caliskan-Can E, Firat H, Ardic S, Simsek B. Influence of gender on $\mathrm{C}$-reactive protein, fibrinogen, and erythrocyte sedimentation rate in obstructive sleep apnea. Antiinflamm Antiallergy Agents Med Chem. 2014;13(1):56-63.

31. Guven SF, Turkkani MH, Ciftci B, Ciftci TU, Erdogan Y. The relationship between high-sensitivity $C$-reactive protein levels and the severity of obstructive sleep apnea. Sleep Breath. 2012;16(1):217-21.

32. WT W, Tsai SS, Shih TS, Lin MH, Chou TC, Ting H, TN W, Liou SH. The impact of obstructive sleep apnea on high-sensitivity C-reactive protein in subjects with or without metabolic syndrome. Sleep Breath. 2015;19(4):1449-57.

33. American Psychiatric Association. Diagnostic and statistical manual of mental disorders. 4th ed. Arlington: American Psychiatric Publishing; 2000.

34. International Diabetes Federation (IDF). The IDF consensus worldwide definition of the metabolic syndrome. 2006. https://www.idf.org/elibrary/ consensus-statements/60-idfconsensus-worldwide-definitionofthemetabolicsyndrome.html. Accessed 27 July 2015.

35. Alberti KGMM, Eckel RH, Grundy SM, Zimmet PZ, Cleeman JI, Donato KA, Fruchart JC, James WPT, Loria CM, Smith SC. Harmonizing the metabolic syndrome a joint interim statement of the international diabetes federation task force on epidemiology and prevention; National Heart, Lung, and Blood Institute; American Heart Association; world heart federation; international atherosclerosis society; and International Association for the Study of obesity. Circulation. 2009;120(16):1640-5.

36. Beck AT, Steer RA, Ball R, Ranieri W. Comparison of Beck depression inventories -IA and -II in psychiatric outpatients. J Pers Assess. 1996;67(3): 588-97.

37. Johns MW. A new method for measuring daytime sleepiness: the Epworth sleepiness scale. Sleep. 1991;14(6):540-5.

38. Morin CM. Insomnia: psychological assessment and management. NY: Guilford Press; 1993.

39. Kushida CA, Littner MR, Morgenthaler T, Alessi CA, Bailey D, Coleman J Jr, Friedman L, Hirshkowitz M, Kapen S, Kramer M, Lee-Chiong T, Loube DL, Owens J, Pancer JP, Wise M. Practice parameters for the indications for Polysomnography and related procedures: an update for 2005. Sleep. 2005;28(4):499-521.

40. Iber C, Ancoli-lsrael S, Chesson A, Quan SF for the American Academy of Sleep Medicine. The AASM manual for the scoring of sleep and associated events: rules, terminology and technical specifications. 1st ed. Westchester: American Academy of Sleep Medicine; 2007.

41. Berry RB, Budhiraja R, Gottlieb DJ, Gozal D, Iber C, Kapur VK, Marcus CL, Mehra R, Parthasarathy S, Quan SF, Redline S, Strohl KP, Davidson Ward SL, Tangredi MM, American Academy of Sleep Medicine. Rules for scoring respiratory events in sleep: update of the 2007 AASM manual for the scoring of sleep and associated events. Deliberations of the sleep apnea definitions task force of the American Academy of sleep medicine. J Clin Sleep Med. 2012;8(5):597-619.

42. Ejaz SM, Khawaja IS, Bhatia S, Hurwitz TD. Obstructive sleep apnea and depression: a review. Innov Clin Neurosci. 2011;8(8):17-25.

43. DiMatteo MR, Lepper HS, Croghan TW. Depression is a risk factor for noncompliance with medical treatment: meta-analysis of the effects of anxiety and depression on patient adherence. Arch Intern Med. 2000; 160(14):2101-7.

44. Dong JY, Zhang YH, Qin LQ. Obstructive sleep apnea and cardiovascular risk: meta-analysis of prospective cohort studies. Atherosclerosis. 2013;229(2):489-95.

45. Wang J, Yu W, Gao M, Zhang F, Li Q, Gu C, Yu Y, Wei Y. Continuous positive airway pressure treatment reduces cardiovascular death and non-fatal 
cardiovascular events in patients with obstructive sleep apnea: a metaanalysis of 11 studies. Int J Cardiol. 2015;191:128-31.

46. Xu S, Wan Y, Xu M, Ming J, Xing Y, An F, Ji Q. The association between obstructive sleep apnea and metabolic syndrome: a systematic review and meta-analysis. BMC Pulm Med. 2015;15:105.

47. Qian Y, Xu H, Wang Y, Yi H, Guan J, Yin S. Obstructive sleep apnea predicts risk of metabolic syndrome independently of obesity: a meta-analysis. Arch Med Sci. 2016;12(5):1077-87.

48. Agrawal S, Sharma SK, Sreenivas V, Lakshmy R. Prevalence of metabolic syndrome in a north Indian hospital-based population with obstructive sleep apnoea. Indian J Med Res. 2011;134(5):639-44.

49. Vancampfort D, Correll CU, Wampers M, Sienaert P, Mitchell AJ, De Herdt A, Probst M, Scheewe TW, De Hert M. Metabolic syndrome and metabolic abnormalities in patients with major depressive disorder: a meta-analysis of prevalences and moderating variables. Psychol Med. 2014;44(10):2017-28.

50. Ishman SL, Cavey RM, Mettel TL, Gourin C. Depression, sleepiness, and disease severity in patients with obstructive sleep apnea. Laryngoscope. 2010;120(11):2331-5.

51. Jacobsen JH, Shi L, Mokhlesi B. Factors associated with excessive daytime sleepiness in patients with severe obstructive sleep apnea. Sleep Breath. 2013;17(2):629-35.

52. Bardwell WA, Moore P, Ancoli-Israel S, Dimsdale JE. Fatigue in obstructive sleep apnea: driven by depressive symptoms instead of apnea severity? Am J Psychiatry. 2003;160(2):350-5.

53. Bjorvatn B, Lehmann S, Gulati S, Aurlien H, Pallesen S, Saxvig IW. Prevalence of excessive sleepiness is higher whereas insomnia is lower with greater severity of obstructive sleep apnea. Sleep Breath. 2015;19(4):1387-93.

54. Nadeem R, Molnar J, Madbouly EM, Nida M, Aggarwal S, Sajid H, Naseem J, Loomba R. Serum inflammatory markers in obstructive sleep apnea: a metaanalysis. J Clin Sleep Med. 2013;9(10):1003-12.

55. Howren MB, Lamkin DM, Suls J. Associations of depression with C-reactive protein, IL-1, and IL-6: a meta-analysis. Psychosom Med. 2009;71(2):171-86.

56. Huang $T L$, Lee $C T$. Low serum albumin and high ferritin levels in chronic hemodialysis patients with major depression. Psychiatry Res. 2007;152(2-3): 277-80.

57. Seda G, Tsai S, Lee-Chiong T. Medication effects on sleep and breathing. Clin Chest Med. 2014;35(3):557-69.

58. Hoflstein V. Relationship between smoking and sleep apnea in clinic population. Sleep. 2002;25(5):519-24.

59. Wetter DW, Young TB, Bidwell TR, Badr MS, Palta M. Smoking as a risk factor for sleep-disordered breathing. Arch Intern Med. 1994;154(19):2219-24.

60. Deleanu OC, Pocora D, Mihălcuță S, Ulmeanu R, Zaharie AM, Mihălțan FD. Influence of smoking on sleep and obstructive sleep apnea syndrome. Pneumologia. 2016;65(1):28-35.

61. Stein MD, Friedmann PD. Disturbed sleep and its relationship to alcohol use. Subst Abus. 2005:26(1):1-13.

\section{Submit your next manuscript to BioMed Central and we will help you at every step:}

- We accept pre-submission inquiries

- Our selector tool helps you to find the most relevant journal

- We provide round the clock customer support

- Convenient online submission

- Thorough peer review

- Inclusion in PubMed and all major indexing services

- Maximum visibility for your research

Submit your manuscript at www.biomedcentral.com/submit
Biomed Central 